\title{
A comprehensive lifecycle evaluation of vertical greenery systems based on systemic indicators
}

\author{
R. M. Pulselli, F. Saladini, E. Neri \& S. Bastianoni \\ Ecodynamics Group, Department of Earth, Environmental and \\ Physical Sciences, University of Siena, Italy
}

\begin{abstract}
Vertical Greenery Systems (VGS) are relatively light structures anchored on building facades with plants embedded on felt layers and nurtured by a hydroponic watering system. These systems can have positive effects on environmental performance at both the building scale (i.e. energy saving for cooling) and the urban scale (i.e. urban heat island effect mitigation). A research project, namely GREENED, has been developed for detecting the environmental profile of VGS based on lifecycle processes. Systemic indicators, such as Carbon Footprint (given in $\mathrm{kg} \mathrm{CO}_{2}$-eq) and eMergy (given in solar emergy Joules - seJ), can provide information on environmental impacts or costs, due to the manufacturing and sustenance of VGS, and benefits, in terms of energy saving or other ecosystems services (e.g. $\mathrm{CO}_{2}$ sequestration by plants). The cost to benefit ratio allows for a comprehensive evaluation of VGS sustainability. Outcomes from a case study (i.e. $98 \mathrm{~m}^{2}$ facade on a $1000 \mathrm{~m}^{3}$ building) reveal that, in given conditions (i.e. massive wall envelope, south-oriented facade, open air-cavity, integrated water harvesting system, local recourse use), environmental costs can be compensated by benefits within 25 years. This allowed for a deeper understanding of lifecycle processes and the conscious use of VGS in an urban context.

Keywords: Carbon Footprint, EMergy Evaluation, global warming, Living Walls, sustainability.
\end{abstract}

\section{Introduction}

Vertical Greenery Systems (VGS) are vegetated structures fixed on building facades. Plants are embedded on a vertical layer, fed by an automatic watering and nurturing system [1]. Among other types of VGS, systems that develop 
hydroponic techniques exploit a textile layer for supporting plants, directly rooted on it. These so-called Living Walls are installed onto rigid PVC panels, which are fastened onto a supporting aluminium framework. Technological components can be therefore easily assembled and periodically repaired.

VGS have been recently studied relative to a set of potential environmental issues. Indoor effects in terms of energy saving were estimated due to the shading effect, the ventilated air cavity behind the vegetated layer and the evapotranspiration of plants, conditioned to climate and orientation [1-9]. Besides effects on indoor climate, the contribution to cool the outdoor ambient temperature in building canyons was also found promising $[3,7,10]$. Moreover, effects on air quality [11] and acoustic insulation [12], due to the leaves, were also documented.

The present research shows outcomes from two environmental accounting methods, namely Life Cycle Assessment (LCA) (limited to the Carbon Footprint) and EMergy Evaluation (EME), in order to investigate the environmental performance of VGS in a Mediterranean climate. As a case study, a VGS was hypothesized installed on a $98 \mathrm{~m}^{2}$ south-oriented façade ( $14 \mathrm{~m}$ length; $7 \mathrm{~m}$ height) of a $1000 \mathrm{~m}^{3}$ building (Figure 1). Based on a simulation model [2] applied to this case study [1], cooling energy saving due to the VGS was found to be around $15 \%$ of the total electricity use for cooling (almost 282 of $1880 \mathrm{kWh} \mathrm{yr}^{-1}$ ).

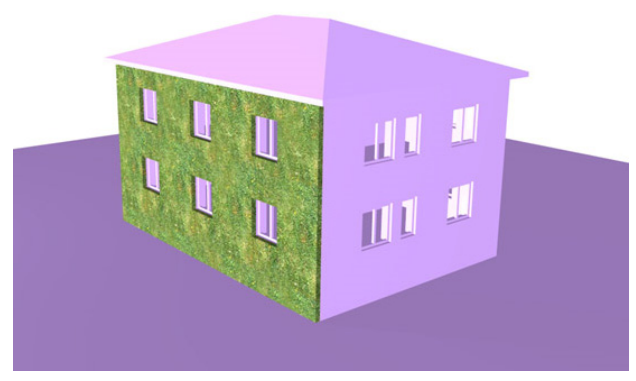

Figure 1: Case study: a $98 \mathrm{~m}^{2}$ south-oriented Vertical Greenery System installed on a $1000 \mathrm{~m}^{3}$ building façade.

\section{Methods}

What relations does a natural-technological system, such as a VGS, establish with its external environment? What are its main sources for supplies? What impacts and emissions are produced? What percentage of the resources utilized is renewable? Environmental accounting methodologies, based on a lifecycle perspective, are useful tools to observe real systems from a systemic viewpoint and provide a general and easily understandable view of the phenomena involved. The observation of a VGS lifecycle is therefore intended as extended to the whole network of processes that, directly or indirectly, participate in its development. 
An energy system diagram (Figure 2) can provide a significant representation of the supply chain of a VGS. This shows the main processes of 1) plants production, 2) plants treatment and VGS panels assembling in the greenhouse and 3) VGS sustenance in time, once installed on the building facade. Processes of transport and the structural elements of the greenhouse are also included. Sources of inputs refer to renewable resources (left side of the rectangle), external resources acquired from the market (up side of the rectangle), and stocks (soil use and materials embedded in structures). This diagram can be interpreted as a proxy of the VGS lifecycle, except for the "end of life" processes that are included in the life cycle inventory but not represented here. Based on this scheme, two methodologies have been implemented.

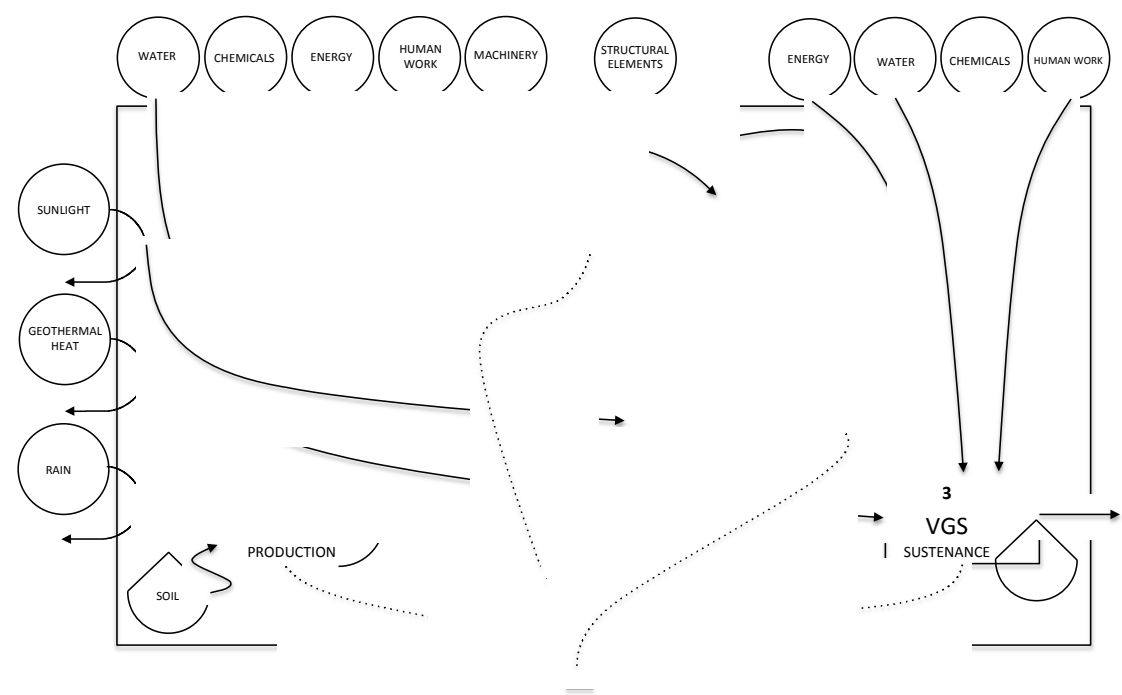

Figure 2: Energy System Diagram of a VGS supply chain.

The Life Cycle Assessment (LCA) is an analytical method for evaluating different categories of environmental impact (ISO 14040-14044: 2006). The Carbon Footprint (ISO 14067: 2013) is one of the indicators calculated through the LCA method, and consists of the estimation of the $\mathrm{CO}_{2}$-equivalent emissions into the atmosphere, generated by all the processes in the life cycle, "from the cradle to the grave," that is, from the retrieval of all the materials used in its making, to the end-of-life treatment once its use has been terminated.

The EMergy Evaluation (EME) aims at the quantitative understanding of the relation between human activities and the biosphere [13, 14]. Different categories of resources can be identified based on their natural formation and regeneration processes. For example, resources such as sunlight, rain, and geothermal heat are renewable, while materials extracted from quarries and mines or fossil fuels are non-renewable. Whether we are dealing with renewable or non-renewable resources, the principle of eMergy states that every flow of matter and energy can 
be expressed in terms of equivalent solar energy (Unit: solar emergy Joule - seJ). EMergy is defined as the quantity of solar energy utilized, directly and indirectly, by a given system or process [14]. In other words, it estimates the amount of solar energy that is progressively stored through a series of transformation processes, starting from primary sources and reaching natural systems and our productive and human settlement systems.

Sustainability indicators based on LCA and EME, developed on the detailed reconstruction of the life cycle processes, reveal information regarding the potential impacts generated by the installation of vertical gardens, as well as their possible environmental benefits.

\section{Results and discussion: Carbon Footprint}

Let's consider the installation of a VGS on the southern facade of our model building. Results from the LCA (Figure 3) show that in 25 years, the overall emission is around $7.3 \mathrm{t} \mathrm{CO}_{2}$-eq that is $294 \mathrm{~kg} \mathrm{CO}_{2}$-eq per year. A significant role is played by structural components $(53 \%)$ (i.e. the aluminium frame and the PVC panels), and transportation (30\%) (plants are usually imported from the Netherlands). The use of tap water for irrigation is another critical factor (11\%) that will affect the VGS sustenance.

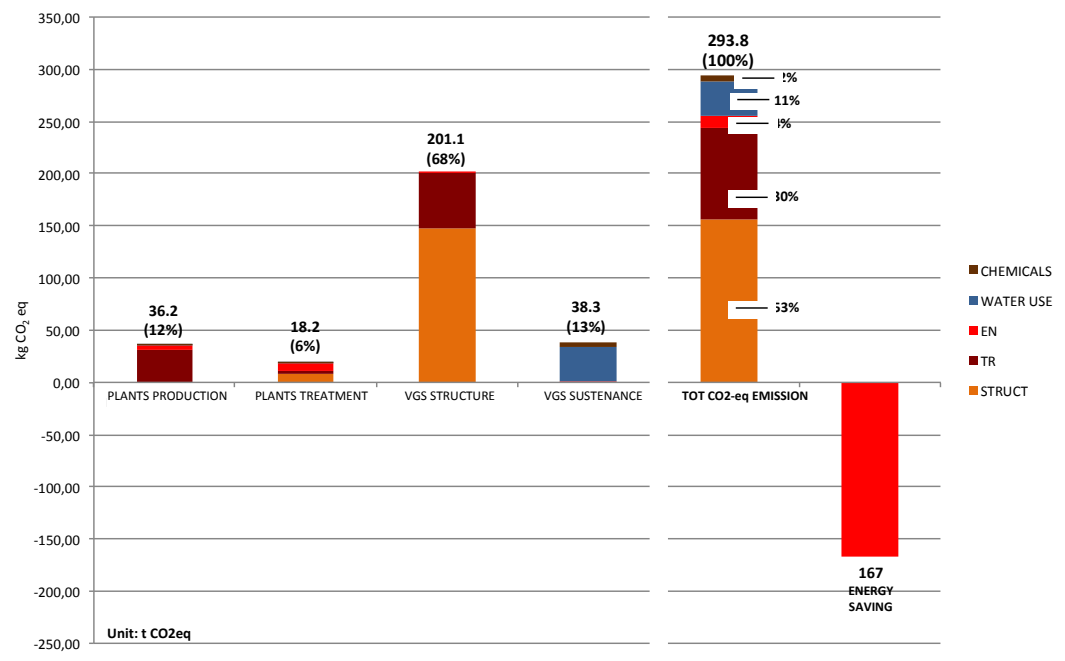

Figure 3: Carbon Footprint: results from the LCA compared to energy saving.

Details from the LCA highlight the main problems and suggest possible solutions to implement a sort of eco-design procedure and reduce impacts. For example, the selection of local suppliers for plants can easily reduce or avoid the impact of transport. Moreover, the consumption of water can be reduced through the installation of an integrated water harvesting system for the collection and use of rainwater. The configuration of this type of scenario could bring the system's 
overall Carbon Footprint to $256 \mathrm{~kg} \mathrm{CO}$-eq per year, with a $13 \%$ reduction in greenhouse gas emissions.

After determining the quantitative "environmental costs" of the VGS, we can estimate its potential "benefits". When considering the Carbon Footprint, two aspects must be greatly highlighted: the first deals with the effect of the VGS on the building envelope's performance; the second with the $\mathrm{CO}_{2}$ sequestration from the atmosphere by the plants. Considering our case study building, it has been estimated that electricity consumption for cooling would result reduced by $15 \%$ due to the VGS installation, which would correspond to $167 \mathrm{~kg} \mathrm{CO}_{2}$-eq per year of atmospheric emissions being avoided.

Furthermore, the estimate of $\mathrm{CO}_{2}$ that is permanently sequestered by the plants has been measured based a specific model [15], that quantifies the accumulation of carbon in a sequence of environmental sections: 1) $\mathrm{CO}_{2}$ absorption by plants; 2) $\mathrm{CO}_{2}$ contained in the residual biomass by pruning operations; 3 ) carbon held in the plants' composting process; 4) carbon deposited onto agricultural soil in the form of compost; 5) carbon assimilated by microorganisms and permanently held in the soil. The results of this analysis show that the plants incorporated into the VGS absorb $\mathrm{CO}_{2}$ from the atmosphere and permanently store it in the soil at a quota of $90 \mathrm{~kg} \mathrm{CO}_{2}$ per year (this value refers to the $98 \mathrm{~m}^{2} \mathrm{VGS}$ with an assorted composition of herbaceous perennial plants). This value is conditioned to the fact that the residual biomass from the pruning and maintenance of plants is gathered and utilized for the production of compost.

Based on the information above, a final balance can be provided in terms of Carbon Footprint and environmental benefits. Against an emissions quota of 256 $\mathrm{kg}$ of $\mathrm{CO}_{2}$-eq per year, the VGS installed on our model building, provided with an integrated water harvesting system and composed of plants produced through a short distribution chain, provides quantifiable environmental benefits. Its effects on the reduction of energy consumption correspond to a quota of $167 \mathrm{~kg} \mathrm{CO}_{2}$-eq per year of emissions avoided. The amount of carbon dioxide permanently sequestered from the plant biomass is $90 \mathrm{~kg} \mathrm{CO}_{2}$ per year. In conclusion, the impacts generated by the life cycle, in terms of Carbon Footprint, will be balanced over a 25-year time span. In other words, these results show a situation of carbon neutrality within 25 years, providing a situation in which the emissions produced during the construction and maintenance phases are balanced by energy saving and the direct sequester of $\mathrm{CO}_{2}$.

\section{Results and discussion: EMergy Evaluation}

Results from EME [1] provides an additional information. Main inputs to processes were classified into renewable resources, human work, chemicals, water use, energy use, transport, structural elements (Figure 4). The total eMergy value of $1.78 \mathrm{E}+16 \mathrm{seJ}$ refers to $98 \mathrm{~m}^{2}$ façade in a $25 \mathrm{yrs}$ estimated lifetime. In particular, renewable resources $(\mathrm{R}=4.6 \%)$ were accounted as independent inflows provided by nature (i.e. solar energy, rain, geothermal heat). Human work ( $\mathrm{HW}=29.2 \%)$ refers to the operations of VGS manufacturing and sustenance. The joint contribution of these two resource categories to the total eMergy is $33.8 \%$. 


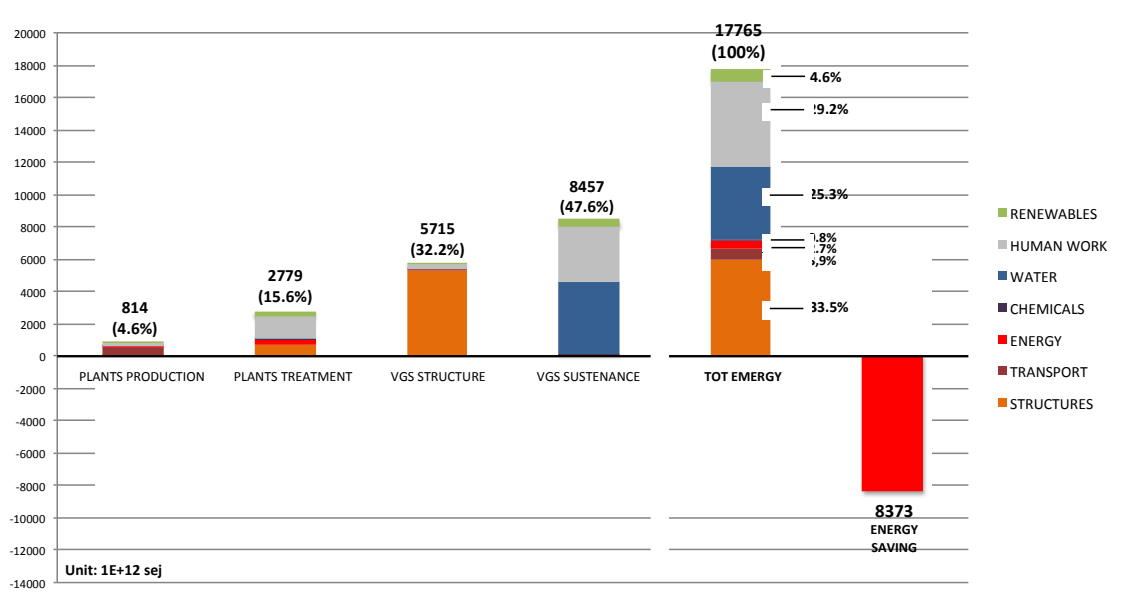

Figure 4: EMergy Evaluation: results compared to energy saving.

The Cost to Benefit Ratio (CBR) was calculated as the ratio of the initial eMergy investment (without renewables and human work) and the yearly energy benefit. Energy saving, in eMergy terms, is around 3.35E + 14 sej yr-1 (in the case of a massive wall envelope). Results show that 'benefits' do not compensate 'costs' within a reasonable lifespan $\left(\mathrm{CBR}_{47}=1\right)$. This result is mainly due to the need of water supply for sustenance. Let's consider an improved scenario: integrating a rainwater harvesting system (water supply in the sustenance phase achieves $25 \%$ of the total eMergy flow) and the use of local resources (plants locally produced instead of imported) are feasible solutions to achieve consistent results: $\mathrm{CBR}_{25}=1.04$. In other words, the initial eMergy investment can be compensated by the environmental benefit within a reasonable time (i.e. $25 \mathrm{yrs}$ ). This demonstrates that VGS determine a moderate and even balanced use of environmental resources.

\section{Conclusion}

The Life Cycle Assessment and EMergy Evaluation were both performed for the assessment of direct and indirect environmental resource appropriation by VGS. This allowed for a deeper understanding of environmental performances back through manufacturing chain processes to the installation on building facade and sustenance.

In particular, results show that VGS, installed on a massive wall envelope, can achieve a condition of comprehensive sustainability in $25 \mathrm{yrs}$ lifetime. This was demonstrated by the LCA, by comparing the Carbon Footprint of VGS manufacturing, maintenance and sustenance $\left(256 \mathrm{~kg} \mathrm{CO}\right.$-eq per year) to the $\mathrm{CO}_{2}$ emission avoided by energy saving (167 kg CO 2 -eq per year) and the $\mathrm{CO}_{2}$ direct absorption by plants ( $90 \mathrm{~kg} \mathrm{CO}$-eq per year). In order to achieve this balanced condition (i.e. carbon neutrality) within 25 years it is nevertheless necessary to 
reduce impacts of transport (plants locally produced instead of imported from the Netherlands) and water use by implementing a water harvesting system.

Similarly, the Cost to Benefits Ratio (CBR), calculated as the ratio between 'direct environmental costs' (eMergy for manufacturing and sustenance) and 'benefits' (saved electricity for cooling, in eMergy terms), showed that benefits can balance costs within 25 years. This means that the initial investment of environmental resources, in eMergy terms, is compensated by the energy saving. Moreover, EME demonstrated to be a valuable method to assess for the contribution of natural resources (renewables such as sunlight, rain and geothermal heat) and human work (i.e. social capital), that provide the $5 \%$ and $30 \%$ of the total eMergy investment, respectively. These two categories of recourses do not represent direct environmental impacts but constitute valuable inputs that contribute to supply the entire lifecycle process and represent a significant added value.

Results from LCA and EME demonstrated that, in certain conditions (i.e. Mediterranean climate context, south-oriented facade and massive envelope), the installation of VGS is a sustainable operation for building retrofitting, not just merely 'green washing'. Outcomes demonstrated that VGS determine a moderate and even balanced use of environmental resources, both in terms of eMergy and Carbon Footprint.

\section{Acknowledgements}

This paper presents results from a research project, namely GREENED, funded by the Tuscan Region, within the program PAR FAS Regione Toscana 2007-2013 line 1.1.a.3. Authors thank SUNDAR Italia s.r.l. for making information on production chain and structural elements available and for its kind collaboration in this research.

\section{References}

[1] Pulselli RM, Pulselli FM, Mazzali U, Peron F, Bastianoni S. Emergy based evaluation of environmental performances of Living Wall and Grass Wall systems. Energy and Buildings 73, 2014, 200-211.

[2] Mazzali U, Peron F, Romagnoni P, Pulselli RM, Bastianoni S. Experimental investigation on the energy performance of living walls in temperate climate. Building and Environment 64, 2013, 57-66.

[3] Wong N. H., Kwang Tan A. Y., Chen Y., Sekar K., Tan P. Y., Chan D., Chiang K., Wong N. C., 2010. Thermal evaluation of vertical greenery systems for building walls. Building and Environment, 45(3), 663-672.

[4] Wong N. H., Kwang Tan A. Y., Tan P. Y., Wong N. C., 2009. Energy simulation of vertical greenery systems. Energy and Buildings 41, 1401-1408.

[5] Kontoleon K. J., Eumorfopoulou E. A., 2010. The effect of the orientation and proportion of a plant-covered wall layer on the thermal performance of a building zone. Building and Environment, 45, 1287-1303. 
[6] Pérez G., Rincón L., Vila A., González J. M., Cabeza L. F., 2011. Behaviour of green fecades in Mediterranean Continental climate. Energy Conversion and Management, 52, 1861-1867.

[7] Tilley D., Price J., Matt S., Marrow B., 2012. Vegetated Walls: Thermal and Growth Properties of Structured Green Facades. Final Report to Green Roofs for Healthy Cities - Green Walls Group. Ecosystem Engineering Design Lab, Environmental Science and Technology Department College of Agriculture and Natural Resources, Maryland, Agricultural Experiment Station, University of Maryland, College Park, p. 163.

[8] Perini K., Ottelé M., Fraaij A. L. A., Haas E. M., Raiteri R., 2011. Vertical greening systems and the effect on air flow and temperature on the building envelope. Building and Environment, 46(11), 2287-2294.

[9] Mazzali U., Peron F., Romagnoni P., Pulselli R. M., Bastianoni S., 2013. Experimental investigation on the energy performance of living walls in temperate climate. Building and Environment, 64, 57-66.

[10] Alexandri E., Jones P., 2008. Temperature decreases in an urban canyon due to green walls and green roofs in diverse climates. Building and Environment, 43(4), 480-493.

[11] Ottelé M., van Bohemen H. D., Fraaij A., 2010. Quantifying the deposition of particulate matter on climber vegetation on living walls. Ecological Engineering, 36(2), 154-162.

[12] Wong N. H., Kwang Tan A. Y., Yok Tan P., Chiang K., Wong N. C., 2010. Acoustics evaluation of vertical greenery systems for building walls. Building and Environment, 45, 411-420.

[13] Odum H.T. Environmental Accounting: emergy and environmental decision making. Wiley, 1996.

[14] Odum H.T. Self Organization, transformity and information. Science, 242, 1988, 1132-1139.

[15] Marchi M., Pulselli RM, Marchettini N, Pulselli FM, Bastianoni S. Carbon Dioxide Sequestration Model of a Vertical Greenery System. Ecological Modelling (in press). 